\title{
User Roles on Peer-to-Peer Sharing Platforms: A Critical Review of the Literature and Recommended Remedies
}

\author{
Sebastian Hermes \\ Technical \\ University of \\ Munich \\ sebastian.hermes@ \\ tum.de
}

\author{
Manuel Maier \\ Technical \\ University of \\ Munich \\ maierman@ \\ in.tum.de
}

\author{
Andreas Hein \\ Technical \\ University of \\ Munich \\ andreas.hein@ \\ tum.de
}

\author{
Markus Böhm \\ Technical \\ University of \\ Munich \\ markus.boehm@ \\ tum.de
}

\author{
Helmut Krcmar \\ Technical \\ University of \\ Munich \\ helmut.krcmar@ \\ $\underline{\text { tum.de }}$
}

\begin{abstract}
The success of sharing platforms such as Airbnb and Uber sparked interests in research, practice, and legislation in equal measures. However, studies about user roles on sharing platforms are very heterogeneous and have yet not dived into the theoretical complexity of these roles. In order to prevent incomparability of results and scattered theory building, this study reviews existing literature and identifies flaws in terminology and conceptualization of user roles and in applied measurement approaches. We discuss why these flaws matter and how they can be resolved. Finally, we propose a research agenda and emphasize to study the role of the prosumer, why different user roles lead to differences in constructs, and how the transition of user roles takes place.
\end{abstract}

\section{Introduction}

In recent years, perspectives on capitalism and consumerism have changed due to economic and institutional reasons. Although individuals have once seen ownership as the most desirable way to have access to products or goods; they are increasingly viewing sharing and paying for temporary access to products and services as an appealing alternative. Growing concerns about climate change and the desire for social embeddedness allowed businesses in the sharing economy to encounter broad interest among the general public and investors [1].

Digital platforms are the enabling technology that orchestrates autonomous agents of supply and demand to interact with each other [2]. Companies in the sharing economy build on digital platforms and can be conceptualized as evolving organizations composed of agents who collaboratively share, consume, and compete [3]. Thus, the roles of agents in an ecosystem are not fixed, but can evolve [4]. An example is the shift of consumers to prosumers based on the governance mechanisms established by the platform owner [5].
Overall, three distinct user roles exist in the sharing economy - namely, consumer, provider and prosumer. While consumers only use and providers only share underutilized assets, prosumers are switching sides and engage in both behaviors. These roles exhibit different motivations and barriers to engage in the sharing economy [3]. The empirical literature suggests that consumers follow economic motives and profit from increased choices and higher flexibility [6], while coping with learning and search costs as well as perceived risks towards the provider. Although building upon sparse research, providers engage for monetary, [7], social-hedonic and altruistic reasons, while needing to overcome privacy concerns and risks of sharing with strangers [3]. Additionally, the bargaining power of the platform differs between consumer and provider. While providers dedicate more time and assets to participate, the platform gains more and more power over them. Consumers, in contrast, are less affected by becoming dependent upon the platform. Whether prosumers represent the sum of both user roles or demonstrate idiosyncratic behaviors remains, to the best of our knowledge, unclear.

To better understand the characteristics and behaviors of these user roles and how users transition into new roles is essential for three reasons. First, to overcome the chicken and egg problem [8] since different roles need different incentives to join the platform ecosystem. Second, to better leverage network effects [9] since prosumers have a greater impact on network effects than those that use a platform at one side. Finally, to cope with role-specific implications for the platform's business model and design such as pricing, rating, openness [5]. To further grow, sharing platform therefore need to balance social and market logics [10] and provide different value propositions to each user role.

The interactions on digital platforms and evolving actors can be demonstrated in the context of peer-topeer (P2P) sharing platforms such as Airbnb or Uber [3]. Airbnb for example, builds upon digital platforms to 
provide a scalable integration of consumers, providers, and prosumers into their platform-mediated ecosystem. The platform orchestrates these user roles by utilizing governance mechanisms such as defining the degree of openness and rating mechanisms [5]. However, Airbnb does not only aim to efficiently integrate and match these different user roles, but it also proactively tries to incentive consumers to evolve towards becoming a prosumer. Thus, they aim to increase the installed base of the prosumers, which, in turn, increases the attractiveness for new users to join [11]. A governance mechanism that Airbnb applies for transiting users to prosumers is to send targeted notifications to consumers, highlighting how much money they could make if they would share their apartment on the platform.

However, prior studies lack on investigating the evolution of actors and neglect the role of providers [12] and especially prosumers. Moreover, when investigating user roles prior work is impaired by inconclusive role derivations and imprecise measurements. Therefore, this study aims to synthesize what current research contributes to our understanding of user roles on $P 2 P$ sharing platforms. More specifically, we aim to investigate how user roles have been derived, what user roles have been identified and how flaws can be resolved. The remainder of this paper is structured as follows: first, we analyze the underlying literature of user roles in linear value chains and on digital platforms; second, we describe our methodology; third, we present how user roles have been derived and what roles have been identified; and finally, we discuss how future endeavors on user roles can be improved and present avenues for future research.

\section{User Roles in Linear Value Chains versus Platform Ecosystems}

The transformation of user roles can be observed when comparing traditional models of value creation with novel approaches to value creation. While traditional value creation takes place in linear value chains, novel approaches build upon the concept of cocreating value $[13,14]$ or by creating value through matching and facilitating transactions between two parties [9]. Understanding which user roles exist and what their purpose is in both approaches helps to illustrate that user roles in platform ecosystems represent a novel phenomenon, which cannot be explained by the logic of linear value chains.

Value creation in linear value chains is closely related to the goods-dominant logic of a firm [15]. It describes the concept of value creation within the boundaries of organizations. The goods-dominant logic posits that products are produced by organizations and purchased and used by consumers. This concept indicates that autonomous agents outside of the organization can only take the role of the consumer. The provision of the good however, takes place within the organization by having different departments or tightlycoupled strategic partners (e.g., supply-chain) collaborating on the production, distribution, and sale of the good. Hence, these tightly coupled departments or providers are restricted regarding their autonomy. While the role of providers may change from direct to indirect value creation within organizations, linear value chains do not intend to outsource these activities or to co-create core assets in partnerships. The core asset of producing and selling the good is kept within the confines of an organization. In other words, the organization does not engage with external parties to provide its core assets. The success of the organization is therefore dependent upon how efficient it can produce and deliver its core assets [16]. The consumer in linear value chains is external. It is considered outside of the organization's boundaries. Therefore, the role of consumers is associated with high degrees of autonomy and loosely coupled relationships with the organization [17]. It is rarely the case that consumers become providers or prosumers. An example of the implications of linear value chains stems from the Hotel industry. Hotels own the real estate that they are offering their guests and control the majority of their value chain. Individuals, however, do not engage in the production of rooms neither are they strongly involved in co-creating peripheral value such as commenting in the social media community.

In contrast, digital platforms as novel mode of value creation orchestrate the co-creation of value in an ecosystem of autonomous agents of supply and demand [2, 18]. Hence, the platform owner orchestrates an ecosystem of supply and demand, where value is cocreated between those two sets of autonomous agents based on interactions with the platform [19]. The role of providers therefore evolved from being located within the firm to being located outside of the firm and its direct control. The provider evolved from a tightly-coupled actor to a loosely-coupled one. The success of the platform is strongly dependent upon how effective it can facilitate the co-creation process between providers and consumers $[16,20]$. For example, Airbnb does not own the rooms that it offers, but helps external providers of rooms to gain visibility and traction. Also, consumers are stronger involved in creating value with Airbnb than with traditional hotels. Consumers rate different 
providers, leave comments, physically interact with the provider, leverage network effects, and might turn into providers themselves.

Digital platforms, therefore, endorse three roles namely the platform owner as a legal entity, provider, and consumer. In contrast, linear value chains comprise the roles of providers and legal entities into one role. Platform-mediated ecosystems demonstrate how to successfully unite platforms and highly autonomous and loosely coupled agents of supply and demand [5]. This concept stems from the service-dominant logic of the firm [19]. Drawing on this logic, Lusch and Nambisan [19] provided examples for the roles of the service provider and service beneficiary, which underscores the evolution of user roles. However, the motives why and the mechanisms how consumer become provider are unclear [21]. Additionally, the context of P2P sharing platforms illustrates that users can not only take one role (consumer or provider); in contrast, they can exercise both roles (prosumer).

\section{Methodology}

To ensure a well-documented search process and a comprehensive literature review, we follow the guidelines by Webster and Watson [22] who provide guidelines for structuring and classifying the results of the literature search.

The literature review was conducted using the scientific databases Web of Science, Business Source Premier (via EbscoHost) and Scopus. The search string combined synonyms for user and role with different terms for the sharing economy ${ }^{1}$.

To ensure that we would find only papers concerning user roles, a proximity operator with $\mathrm{N}=1$ was used. This operator means that a maximum of one other word was allowed to be between the words for user and group while the order of the words made no difference. An additional benefit of using this operator is that it prevents being too narrow in the search string. This is particularly helpful for our purpose because terms like "group of customers" were included in the results. We reduced the initial list of hits by accounting for duplicates, false positives and paper not concerning the sharing economy. After conducting a backward- and a forward-search the final set contained 22 articles.

We analyzed all articles in-depth by thoroughly inspecting the entire manuscript on how user roles had been derived and what user roles had been identified,

\footnotetext{
1 Search String: ("p2p economy" OR "peer-to-peer economy" OR
}

"sharing economy" OR "asset sharing" OR "collaborative rather than scanning abstract and conclusion. In this process we extracted the methodology for clustering users, the cluster variables, the investigated roles and the key findings. Additionally, we categorized which types of platforms the articles studied based on the typology provided by Gerwe and Silva [3] and Schor and Fitzmaurice [23].

\section{Results}

The analysis of the articles revealed that the research stream of user roles on sharing platforms is still in its infancy. This observation stems from the ranking of the articles, the type of data collected and the identification of user roles. Further review criteria as well as the key findings of the articles, are presented in table 1. Regarding the ranking of the 22 articles, we notice that none of them was from the Senior Scholars' Basket of Eight or from the Financial Time 50 ranked journals.

Concerning the approaches to identify user roles, we find that around half of the articles conducted a literature review or investigated user roles by defining them ex ante. In both cases, the consensus was that two user roles exist. The first role describes the provision of a service or a good and the second role describes the consumption of it. Some authors mentioned that individuals could switch between the roles [24, 25]; however, they do not consider these individuals as another user role (prosumer) with distinct characteristics. Among the authors who performed a cluster analysis ex-post, the clusters were mainly created based on respondents' motivation to engage in sharing platforms. The motivation was usually measured by economic benefits, the desire to meet new people and interact with them or the importance to regularly use different goods. The last dimension refers for example to people who value driving different cars each month. In that case it is more attractive to use a car-sharing platform than to buy a car. Guttentag, et al. [6], for example, derived five user cluster based on different motivational factors which they describe as money savers, home seekers, collaborative consumers, pragmatic novelty seekers and interactive novelty seekers. However, all articles who performed cluster analyses investigated only the consumer role. Solely Wilhelms, et al. [7] studied the motivation of consumers and providers separately. The remaining articles clustered users based on age [26], accommodation type [27], whether providers should have a trade union [28] and based on the behavior while

consumption") AND ((user OR consumer OR customer OR provider) N1 (class OR type OR profile OR identity OR group OR role OR segmentation)) 


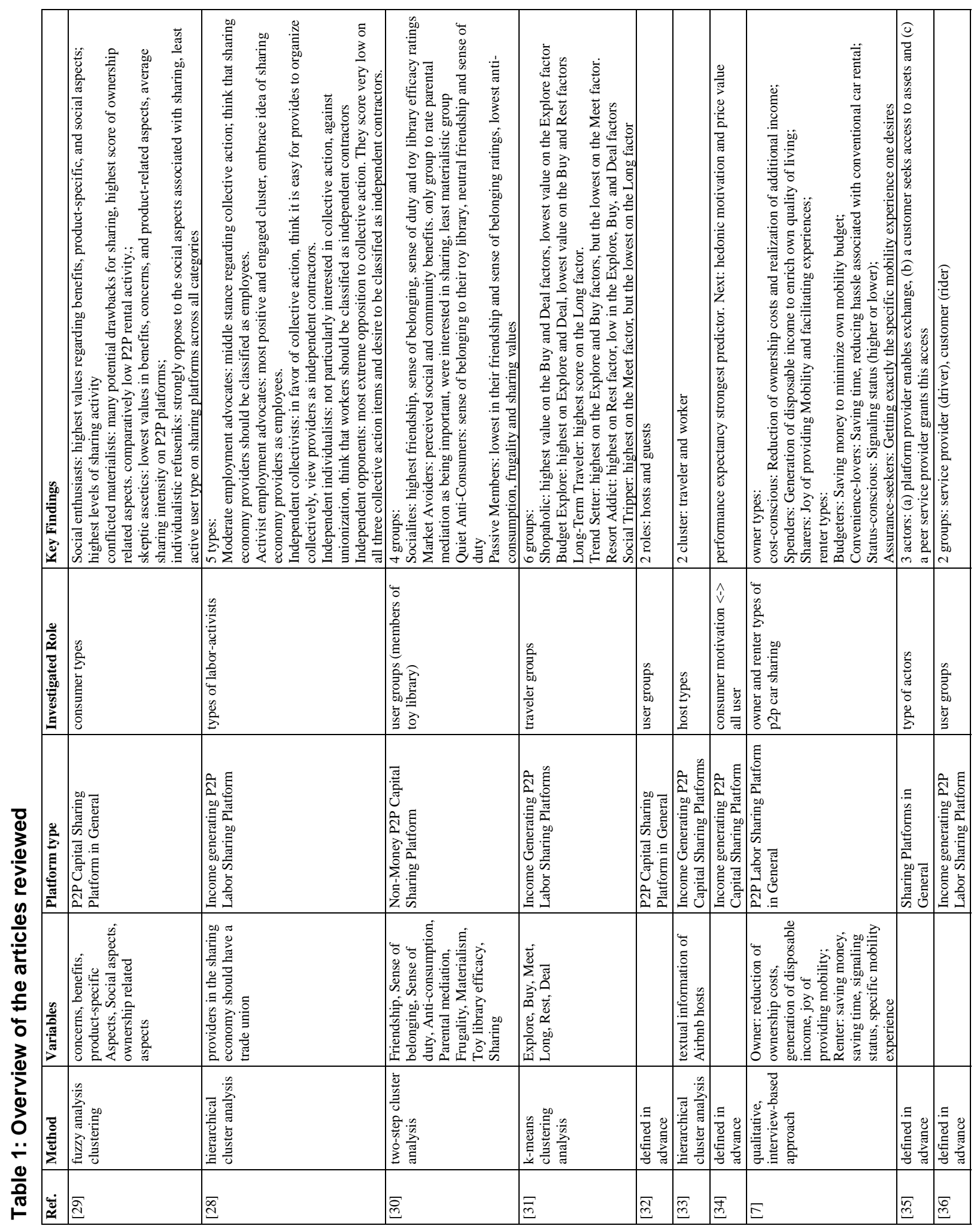




\begin{tabular}{|c|c|c|c|c|c|c|c|c|c|c|c|c|}
\hline & 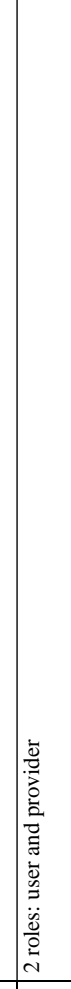 & 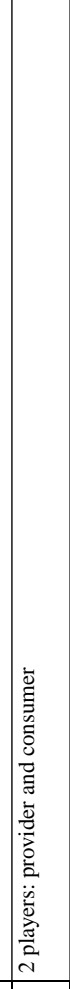 & 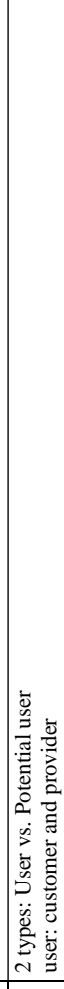 & 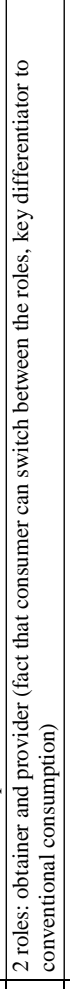 & 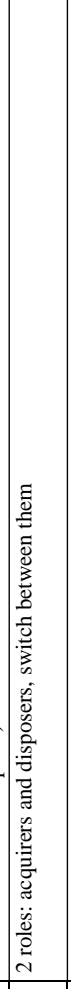 & 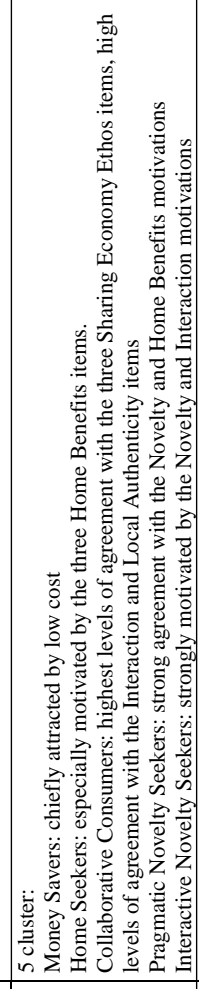 & 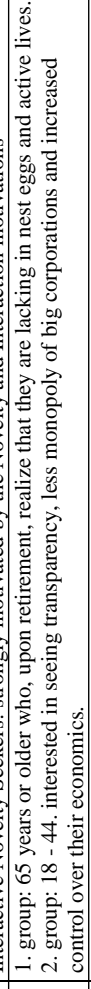 & 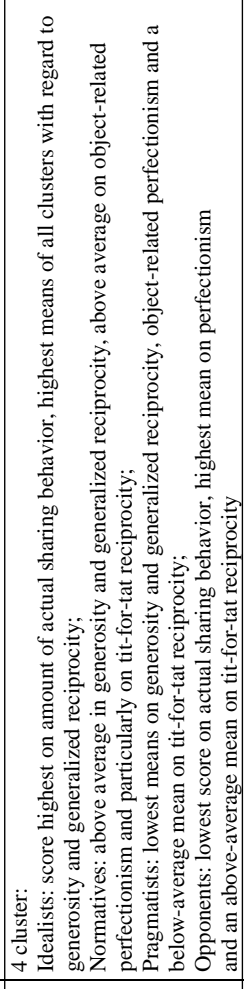 & 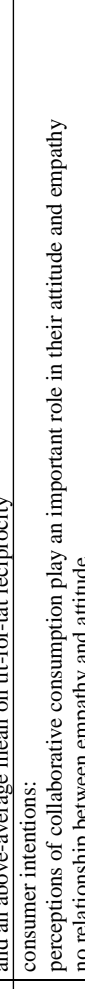 & 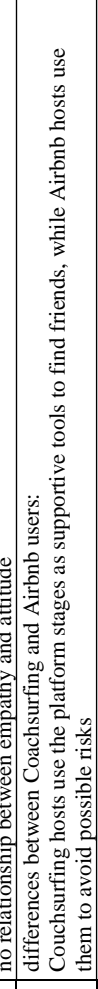 & 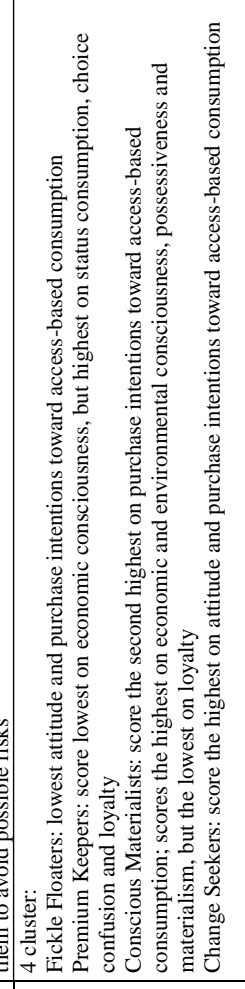 & 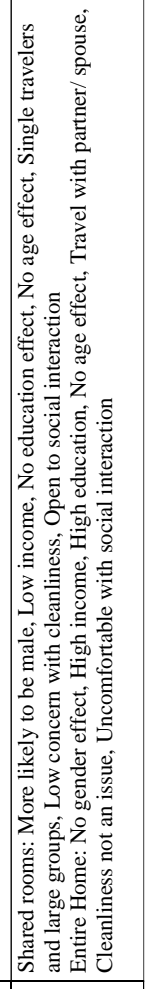 \\
\hline & 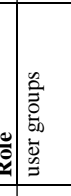 & 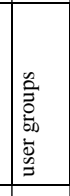 & 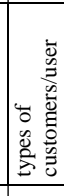 & 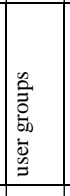 & 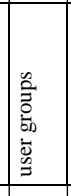 & 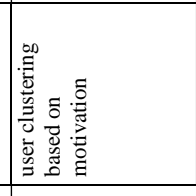 & 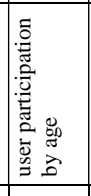 & 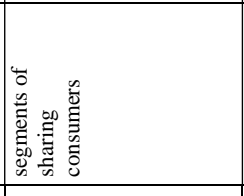 & 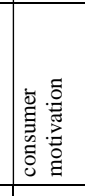 & 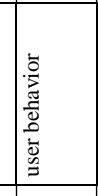 & 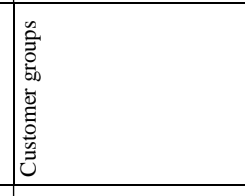 & 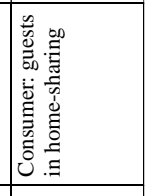 \\
\hline & 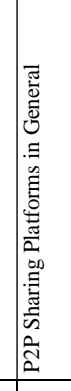 & 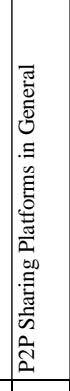 & 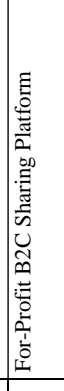 & 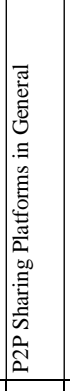 & 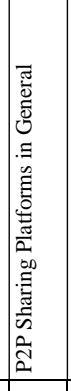 & 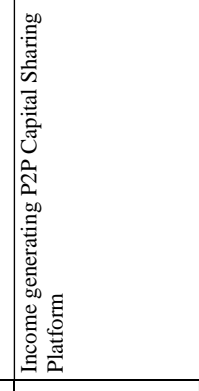 & 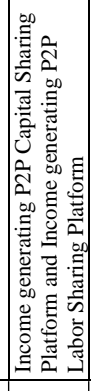 & & 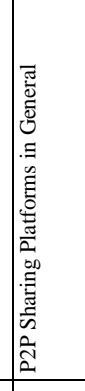 & 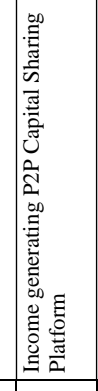 & 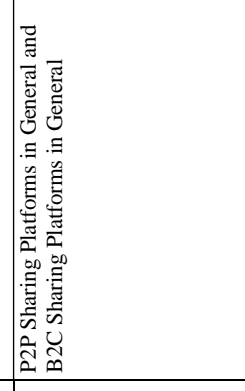 & 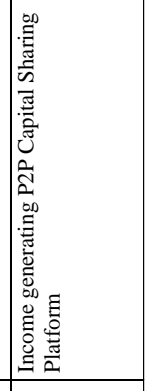 \\
\hline 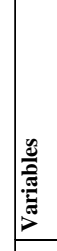 & & & & & & 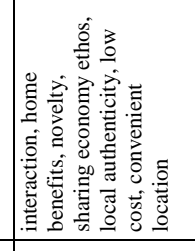 & & 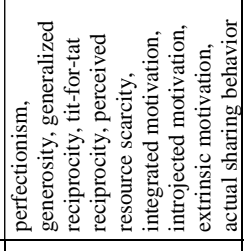 & & & 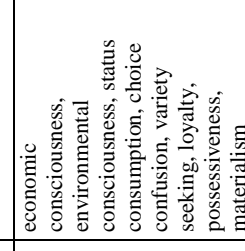 & 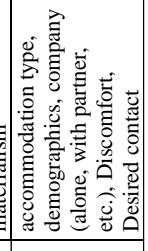 \\
\hline 总 & 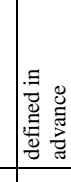 & {$\left[\begin{array}{l}0 \\
0\end{array}\right.$} & & 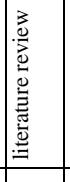 & 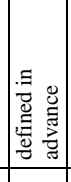 & 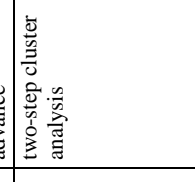 & 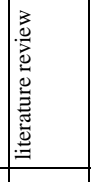 & 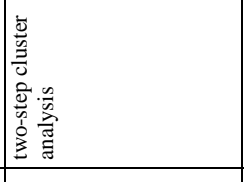 & 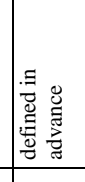 & 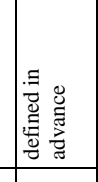 & 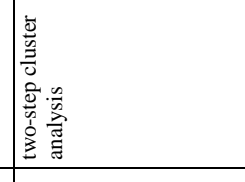 & 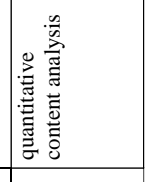 \\
\hline$\ddot{\Xi}$ & 胥 & \begin{tabular}{|l}
$\infty$ \\
$\stackrel{\infty}{\check{n}}$
\end{tabular} & 菟 & 壱 & $\sqrt[\bar{\beth}]{\mathrm{d}}$ & $\underline{\sigma}$ & 迅 & 焉 & $\bar{\Xi}$ & $\overline{\mathbb{I}}$ & $\overline{\mathscr{I}}$ & $\bar{\Xi}$ \\
\hline
\end{tabular}


traveling [31]. This indicates that current research on user roles are exploring a variety of clustering options. While these investigations provide valuable knowledge to this stream, the heterogeneity of measurements and analyses complicate the comparability of results and therefore hamper consistent theory building.

Regarding the type of data collected, we observe that the studies gather perceptional and ordinal data through questionnaires, while actual behavior and metric data is not being collected.

Concerning the platform type, we find that few articles concentrated on a specific type of sharing platform. Instead, most of the articles investigated for example all accommodation sharing platforms or all sharing platforms. The articles which investigated one specific platform type mainly analyzed user roles on Airbnb or Uber. Few articles looked at other types of sharing platforms like car, tool, or time sharing.

\section{Discussion}

While research deriving and describing different types of users on $\mathrm{P} 2 \mathrm{P}$ sharing platforms is still in its infancy, it indicates to be ambiguous and to lack theoretical ground to capitalize upon the complexity of user roles. Such blurriness stems from two issues. The first issue results from inconclusive role derivations and the second from imprecise measurements. Inconclusive role derivations relate to neglecting that sharing platforms comprise two behaviors: consuming and/or providing. Imprecise measurements relate to neglecting different perspectives and objects respondents need to consider when answering questions about sharing platforms. Do respondents take the role of consumers, providers, prosumers, or non-users? Do respondents answer questions about the platform owner, the consumer, the provider, or the shared good or service? Do respondents refer to sharing accommodations, cars, tools, or services? Such negligence hampers the precise interpretation of collected data and may lead to flawed conclusions. It is crucial, however, to put findings into perspective. Is the consumer referring to the platform owner, the provider of accommodations, or the accommodation itself? Is someone who consumes and provides tools referring to the trustworthiness of the platform owner when consuming or to the trustworthiness of the platform owner when providing?

Neunhoeffer and Teubner [29], for instance, describe their sample as "prototypical consumers" referring to internet users in general and their motives for and against using sharing platforms. Among other things, they measure trust and social influence. However, measuring trust through general items like
"Other PPS [Peer-to-peer sharing] users are trustworthy" or social influence by "People who are important to me think that I should participate in PPS" complicate unambiguous sense-making [29]. We argue that the findings would be more transparent and reliable if the constructs had been adapted to the research purpose in more detail. We argue that constructs need to be considered individually towards each ecosystem actor (platform owner, consumer, and provider). The item of social influence leaves much space regarding the interpretation of "participate." Does the respondent refer to consuming and/or providing? Including such nuances could reveal more granular insights and straightforward data interpretation and sense-making. Otherwise one could encounter the problem that a provider receives questions about consuming. In this case the provider never engaged in the activity of consuming and will only be able to indicate an imagined answer not a perceived answer. The same issue occurs if consumers receive questions about providing or if prosumers don't understand to which activity (consuming or providing) they should relate their answer to.

Lawson, et al. [43] aim to classify respondents' motivations for access-based consumption and describe their sample as "any adult with an MTurk account." However, earlier in the paper they suggest multiple constructs that "will motivate consumers to engage in access-based consumption" [43]. We feel that using any adult and consumer simultaneously creates intransparency in the findings. Any adult refers to individuals older than 18 , from which we do not know if they engage in sharing platforms or not. In contrast, consumers indicate that the respondent is a user. We argue, therefore, that using terms consistently is crucial to derive accurate findings. Moreover, the term consumer implies different types of consumer. Consumers may engage in consuming and providing or consumers may engage only in consuming. Distinguishing both terms could help to generate findings that reflect the phenomena under study more accurately.

Similar to previous studies, Guttentag, et al. [6] conducted a motivation-based segmentation. The authors state that they investigated individuals who "have been significantly involved in the decision to choose Airbnb accommodation" or in other words, they chose to investigate consumers. We argue that in this study the term consumer implies an ambiguous meaning and that the validity of findings could be improved by taking different types of consumers into account - the ones that consume and provide (prosumer) and the ones that only consume (consumer). Both groups seem to demonstrate different behaviors and attitudes within the 
sharing ecosystem and its various actors [44, 45]. However, we endorse the distinction between the host (provider) and Airbnb (platform owner) made in the measurements. This differentiation is a good example of taking different roles into account, which is necessary to draw precise conclusions on sharing platforms.

Similar issues concerning terminological subtleties can also be found in the studies of Lutz and Newlands [27], Tussyadiah and Park [33], Newlands, et al. [28], and Wilhelms, et al. [7], who assume that provider and consumer are distinct entities, without taking the role of prosumer into account. Moreover, we argue that in the study of Tussyadiah and Park [33] using integrity, benevolence, and ability to measure trust in providers is less suitable than modifying trust in platforms to fit the context of providers. This could be done by asking: I trust [providers on] peer-to-peer accommodation rental services. This way, future studies investigating how providers are perceived can adapt the scale to their research purpose. Using the same scale with minor modifications could also increase the comparability of trust in platforms, providers, and consumers.

Overall, we argue that the terminology of consumers is not homogeneous across studies and that four distinct user roles exist on sharing platforms: non-user, consumer, provider, and prosumer. The lack of precise definitions may affect the comparison of findings between different studies. Moreover, we argue that the methodology to assess user groups is also heterogeneous. This includes the type of object that is shared (e.g., accommodation, car, service) and the modification of measurements (sharing platforms in general vs. perceptions towards specific roles in the sharing economy). This heterogeneity may falsely lead to contradictory results and needs to be carefully addressed. We argue that taking terminology and methodology into consideration is vital to derive rigorous findings and accurate conclusions. We find support for our claim in related literature [12, 44, 46].

In the following section, we go beyond discussing our terminology of user roles and provide theoretical arguments on how and why these user roles differ from one another. Our arguments build upon different sharing categories that exist within the sharing economy.

The first differentiating factor is the type of provider. Schor and Fitzmaurice [23] and Wirtz, et al. [47] agree that provider on sharing platforms must be distinguished according to whether resources are provided by another peer in case of $\mathrm{P} 2 \mathrm{P}$ sharing or by a B2C sharing company. This differentiation is vital to consider when studying sharing platforms because respondents' answers may differ based on whether they refer to a $\mathrm{P} 2 \mathrm{P}$ or a $\mathrm{B} 2 \mathrm{C}$ provider. For example, their perception of the trustworthiness of peers and businesses may strongly differ because peers, in contrast to businesses, have less reputation, no external credibility, and a brief history of operation. Therefore, consumers need much trust in peers than in business in order to execute the sharing transaction.

The other factor differentiating sharing platforms is the platform orientation. According to Schor and Fitzmaurice [23] and Wirtz, et al. [47] platform orientation comprises non-profit and for-profit orientation, while Gerwe and Silva [3] also consider cost-covering as the third dimension of platform orientation. We argue that the platform orientation is another factor that influences respondents' answers. For example, the perception of risk may differ whether respondents refer to a non-profit or for-profit platform. While for-profit platforms possess financial resources to account for liabilities or consistent service uptime, nonprofit platforms may be more risk-prone regarding these aspects.

Furthermore, Gerwe and Silva [3] distinguish between the type of sharing: capital and labor. While some platforms enable the sharing of physical assets like accommodations, cars or tools, other platforms focus on sharing skills, abilities or time (e.g., babysitting or construction work). We argue that the type of sharing is also a crucial factor in influencing respondents' answers. First, sharing capital requires consumers to compensate providers. This stands in contrast to sharing labor which causes the provider of a task to be the consumer of the solution. Hence, the provider is compensating the consumer. We argue that sharing capital and labor refer to reversed transactions and need to be accounted for. Second, perceptions of the transaction differ based on the good or service that is being exchanged. For example, while a consumer of a shared car may require more trust regarding the quality and safety of the car, a consumer of construction work requires less trust towards the service she is being offered. Similarly, a provider of tools will probably perceive the transaction of sharing tools less risky than a provider of babysitting hours.

Therefore, we emphasize that research on user roles in the sharing economy needs to take all of the above aspects into account because these aspects change the way respondents' answer research questions. The variety in answers is due to the different platforms respondents use and due to the different activities (consuming and/or providing) they engage in. Therefore, these aspects need to be captured in order to control for them afterwards. Moreover, these aspects also demonstrate that the proposed user roles are indeed distinct and they lead to differences in important 
constructs such as trust or risk. We conclude that by considering these aspects better interpretation of results and more transparent and reproducible studies will be possible.

\section{Future research and limitations}

We propose four avenues for future research. First, we propose to move beyond studying consumers on sharing platforms. Promising and valuable endeavors emerge from investigating providers and prosumers. Providers can be explored from two perspectives. On the one side from the perspective of providers as peers and on the other side from the perspective of providers as legal businesses such as hotels for example. Research on prosumers is of practical importance since users switching sides have a greater impact on network effects than those that use a platform at one side. Integrating the dual role of users to our current understanding of user roles enhance the validity of future studies.

Second, we outlined how and why the three user roles of consumer, provider, and prosumer differ. Therefore, we call for empirical studies to test whether these roles lead to differences in important constructs. For example, one could test to which degree the perception of the platform owner's trustworthiness differs between consumer, provider, and prosumer. This implies that trust is related to a specific entity such as the platform owner. We argue that omitting the connection to a specific entity threatens the validity of studies since it is not possible to trace back to which entity the respondent was referring her answers to. Connecting constructs to a specific entity also allows to avoid the problem that a role needs to answer questions about its own role. This would be the case if consumers need to answer questions about other consumers. Since only providers and prosumers engage with consumers it does not make sense to provide these questions to consumers. As a result, the consumer would indicate an imagined answer instead of a perceived answer. In other words, she would need to guess instead of indicating her actual perception.

Third, we encourage to investigate other platforms types besides Airbnb and Uber and to gather data about users' actual behavior on P2P sharing platforms. Collecting metric and objective data enables the research stream on user roles to detach itself from perceptional research and to follow a new analytical approach yielding new theoretical perspectives.

Finally, we propose to study the transition of user roles. To which role do platform owners try to convert non-user onto their platform? Do platform owners incentivize or subsidize becoming a consumer or a provider in the first place? Which role is more receptive to be converted towards the role of prosumer? By which mechanisms do platform owners try to convert consumers and providers towards the role of prosumer?

The results of our study underlie several limitations. First, the literature search may not cover all relevant studies due to the choice of outlets and keywords. For example, alternative terms for the concept of platform ecosystems such as software ecosystem or partnership network may yield additional articles. Second, the subjective development and analysis of the concept matrix build our theoretical foundation to assess user roles on $\mathrm{P} 2 \mathrm{P}$ sharing platforms. In the course of this process, some insights may have been lost and are not represented in our results. A different focus or extraction approach may generate additional insights. Third, the issues for future research that we derived from our findings may be influenced by the authors' perspective and the topic. Therefore, open issues may exist and can be revealed in future work.

\section{Conclusion}

Research about user roles on sharing platforms is getting more and more attention in the literature. The phenomenon of sharing platforms allows users to engage in new roles such as the role of provider and prosumer and to co-create value with the platform owner. This stands in contrast to linear value chains in which the role of the provider is within the firm and in which consumers do not actively contribute to the creation of the core asset.

Previous research that aims to understand user roles in the sharing economy however, lacks precise terminology and a shared conceptualization of user roles and demonstrates flaws in applied measurement approaches. This hampers comparability of results and leads to scattered theory building.

Our objective was therefore to investigate how user roles have been derived and what user roles have been identified. We found that user roles are identified by literature reviews, defining them ex-ante or exploring them ex-post through cluster analysis. In the first two cases, the finding is that the roles of consumer and provider exist, neglecting the role of prosumers. In the latter, studies mainly search for clusters within the role of consumers. Additional roles have been scarcely researched. Prior studies find around four consumer cluster.

Our study has three contributions. First, we synthesize and discuss prior findings and methodologies about user roles on sharing platforms. Second, we call for homogenous terminology and more precise 
measurements to increase comparability of findings. Finally, we demonstrate how and why user roles differ. This represents the groundwork for assessing whether these roles lead to differences in important constructs, how actors evolve from one role into another and that platforms need to incentivize such switching behavior for each group individually.

\section{References}

(* included in the literature analysis)

[1] Hamari, J., M. Sjöklint, and A. Ukkonen, The sharing economy: Why people participate in collaborative consumption. Journal of the Association for Information Science and Technology, 2016. 67(9): p. 2047-2059.

[2] de Reuver, M., C. Sørensen, and R.C. Basole, The digital platform: a research agenda. Journal of Information Technology, 2017. 33(2): p. 124-135.

[3] Gerwe, O. and R. Silva, Clarifying the sharing economy: conceptualization, typology, antecedents, and effects. Academy of Management Perspectives, 2018(In Press).

[4] Gawer, A., Bridging differing perspectives on technological platforms: Toward an integrative framework. Research policy, 2014. 43(7): p. 1239-1249.

[5] Tiwana, A., B. Konsynski, and A.A. Bush, Research commentary-Platform evolution: Coevolution of platform architecture, governance, and environmental dynamics. Information systems research, 2010. 21(4): p. 675-687.

[6] * Guttentag, D., et al., Why Tourists Choose Airbnb: A Motivation-Based Segmentation Study. Journal of Travel Research, 2018. 57(3): p. 342-359.

[7] * Wilhelms, M.-P., K. Merfeld, and S. Henkel, Yours, mine, and ours: A user-centric analysis of opportunities and challenges in peer-to-peer asset sharing. Business Horizons, 2017. 60(6): p. 771-781.

[8] Caillaud, B. and B. Jullien, Chicken \& egg: Competition among intermediation service providers. RAND journal of Economics, 2003. 34(2): p. 309-328.

[9] Eisenmann, T., G. Parker, and M.W. Van Alstyne, Strategies for two-sided markets. Harvard business review, 2006. 84(10): p. 92.

[10] Milanova, V. and P. Maas, Sharing intangibles: Uncovering individual motives for engagement in a sharing service setting. Journal of Business Research, 2017. 75: p. 159-171.
[11] Henfridsson, $\mathrm{O}$. and $\mathrm{B}$. Bygstad, The generative mechanisms of digital infrastructure evolution. MIS quarterly, 2013. 37(3): p. 907-931.

[12] Tussyadiah, I.P. and J. Pesonen, Drivers and barriers of peer-to-peer accommodation stay-an exploratory study with American and Finnish travellers. Current Issues in Tourism, 2016. 21(6): p. 703-720.

[13] Payne, A.F., K. Storbacka, and P. Frow, Managing the co-creation of value. Journal of the academy of marketing science, 2008. 36(1): p. 83-96.

[14] Hein, A., et al., The emergence of native multi-sided platforms and their influence on incumbents. Electronic Markets, 2019: p. 1-17.

[15] Vargo, S.L. and R.F. Lusch, Service-dominant logic: continuing the evolution. Journal of the Academy of marketing Science, 2008. 36(1): p. 1-10.

[16] Parker, G.G., et al., Platform revolution: How networked markets are transforming the economy and how to make them work for you. 2016: WW Norton New York.

[17] Danneels, E., Tight-loose coupling with customers: the enactment of customer orientation. Strategic Management Journal, 2003. 24(6): p. 559-576.

[18] Hermes, S., M. Böhm, and H. Krcmar. Business Model Innovation and Stakeholder Exploring Mechanisms and Outcomes of Value Creation and Destruction. in 14th International Conference on Wirtschaftsinformatik. 2019. Siegen, Germany.

[19] Lusch, R.F. and S. Nambisan, Service innovation: A service-dominant logic perspective. MIS quarterly, 2015. 39(1): p. 155-176.

[20] Clemons, E., et al. American Domination of the Net: A Preliminary Ethnographic Exploration of Causes, Economic Implications for Europe, and Future Prospects. in Proceedings of the 52nd Hawaii International Conference on System Sciences. 2019.

[21] Jacobides, M.G., C. Cennamo, and A. Gawer, Towards a theory of ecosystems. Strategic Management Journal, 2018. 39(8): p. 2255-2276.

[22] Webster, J. and R.T. Watson, Analyzing the past to prepare for the future: Writing a literature review. MIS quarterly, 2002: p. xiii-xxiii.

[23] Schor, J.B. and C.J. Fitzmaurice, Collaborating and connecting: the emergence of the sharing economy. Handbook of research on sustainable consumption. 2015, Cheltenham, UK: Edward Elgar. 
[24] * Ertz, M., F. Durif, and M. Arcand, Collaborative consumption: Conceptual snapshot at a buzzword. Journal of Entrepreneurship Education, 2016. 19(2): p. 1-23.

[25] * Ertz, M., A. Lecompte, and F. Durif, Dual roles of consumers: Towards an insight into collaborative consumption motives. International Journal of Market Research, 2017. 59(6): p. 725-748.

[26] * Hasan, R. and M. Birgach. Critical success factors behind the sustainability of the Sharing Economy. in 2016 IEEE/ACIS 14th International Conference on Software Engineering Research, Management and Applications, SERA 2016. 2016.

[27] * Lutz, C. and G. Newlands, Consumer segmentation within the sharing economy: The case of Airbnb. Journal of Business Research, 2018. 88: p. 187-196.

[28] * Newlands, G., C. Lutz, and C. Fieseler, Collective action and provider classification in the sharing economy. New Technology, Work and Employment, 2018. 33(3): p. 250-267.

[29] * Neunhoeffer, F. and T. Teubner, Between enthusiasm and refusal: A cluster analysis on consumer types and attitudes towards peer-to-peer sharing. Journal of Consumer Behaviour, 2018. 17(2): p. 221-236.

[30] * Ozanne, L.K. and P.W. Ballantine, Sharing as a form of anti-consumption? An examination of toy library users. 2010. 9(6): p. 485-498.

[31]* Ryu, S., K. Choi, and D. Cho. Behaviour-Based Market Segmentation of Travellers and Their Different Activities at Peer-to-Peer Online Travel Marketplace. 2018. Cham: Springer International Publishing.

[32] * Tussyadiah, I.P. An Exploratory Study on Drivers and Deterrents of Collaborative Consumption in Travel. 2015. Cham: Springer International Publishing.

[33] * Tussyadiah, I.P. and S. Park, When guests trust hosts for their words: Host description and trust in sharing economy. Tourism Management, 2018. 67: p. 261-272.

[34] * Wang, M. and L. Li. Who Wants to Live Like a Local?: An Analysis of Determinants of Consumers' Intention to Choose AirBNB. in 2017 International Conference on Management Science and Engineering (ICMSE). 2017. IEEE.

[35] * Benoit, S., et al., A triadic framework for collaborative consumption (CC): Motives, activities and resources \& capabilities of actors. Journal of Business Research, 2017. 79 : p. 219-227.
[36] * Boateng, H., J.P.B. Kosiba, and A.F. Okoe, Determinants of consumers' participation in the sharing economy. International Journal of Contemporary Hospitality Management, 2019. 31(2): p. 718-733.

[37] * Bocker, L. and T. Meelen, Sharing for people, planet or profit? Analysing motivations for intended sharing economy participation. Environmental Innovation and Societal Transitions, 2017. 23: p. 28-39.

[38] * Chica, M., et al. An evolutionary trust game for the sharing economy. in 2017 IEEE Congress on Evolutionary Computation, CEC 2017 - Proceedings. 2017.

[39] * Donghae, K. and Y.C. Cho, Investigating the Impact of Utilities on Customer Attitude, Satisfaction, Comparative Analysis of B2C Car Sharing: Korea vs. Japan. Journal of Marketing Thought, 2018. 5(2): p. 1-11.

[40] * Hellwig, K., et al., Exploring Different Types of Sharing: A Proposed Segmentation of the Market for "Sharing" Businesses. Psychology \& Marketing, 2015. 32(9): p. 891-906.

[41] * Hwang, J. and M.A. Griffiths, Share more, drive less: Millennials value perception and behavioral intent in using collaborative consumption services. Journal of Consumer Marketing, 2017. 34(2): p. 132-146.

[42] * Jung, J. and K.-P. Lee. Curiosity or Certainty?: A Qualitative, Comparative Analysis of Couchsurfing and Airbnb User Behaviors. in Proceedings of the 2017 CHI Conference Extended Abstracts on Human Factors in Computing Systems. 2017. ACM.

[43] * Lawson, S.J., et al., Freedom from ownership: An exploration of access-based consumption. Journal of Business Research, 2016. 69(8): p. 2615-2623.

[44] Hawlitschek, F., T. Teubner, and H. Gimpel, Consumer motives for peer-to-peer sharing. Journal of Cleaner Production, 2018. 204: p. 144-157.

[45] Teubner, T. and F. Hawlitschek, The economics of peerto-peer online sharing. The rise of the sharing economy: Exploring the challenges and opportunities of collaborative consumption. 2018, Santa Barbara, Califorina.

[46] Hawlitschek, F., T. Teubner, and C. Weinhardt, Trust in the sharing economy. Die Unternehmung, 2016. 70(1): p. 2644.

[47] Wirtz, J., et al., Platforms in the Peer-to-Peer Sharing Economy. Journal of Service Management, 2019(forthcoming). 